\title{
Optimization of the GDP Equation
}

\section{Cusack PTE*}

DULE, 1641 Sandy Point Rd, Saint John, NB, Canada

\begin{abstract}
Economics are now using Engineering Mechanics to solve Economic problems. In this paper, we use Astrotheology Mathematics to optimize the GDP equation. This Econphyscis can be used to program a computer to create a real-time computer program to solve unknown variable, such as consumption, in the broad economy.
\end{abstract}

Keywords: GDP equation; Astro-theology mathematics; Permittivity; Stiffness; Consumption

\section{Introduction}

In a previous paper and book under the title of Physical Economics, the author considered making use of Engineering Structural mechanics to model the economy. Different characteristic, such as the load on a simply supported beam can be thought of economically and the distribution of wealth across the economy. His deflection of the bean can be considered as the GDP growth. In a series of papers, I considered the solution to these stercoral engineering problems in a successful attempt to model the economy [1].

Things in Economics that can't be measured can be measured in Physics and vice versa. Here we consider the well-known GDP equation and its optimization. We make use of facts from Physics, such as the number of elements in the Periodic Table of the elements to calculate Y. We make us of the pervious paper by the author Cusack US Economy equation to solve this optimization problem so that ideal levels of government spending, Consumption, Savings and Investment can be determined algebraically [2] . This could be programmed in a computer algorithm if another paper in this economics series published in Global economics Journal is considered. We begin with the GDP equation $[3,4]$.

$$
\mathrm{Y}=\mathrm{C}+\mathrm{G}+\mathrm{I}+\mathrm{S}+(\mathrm{EX}-\mathrm{IM})
$$

YGDP

\section{$\mathrm{C}=$ Consumption}

G=government Spending

$\mathrm{I}=$ Foreign Investment

$S=$ Savings

$\mathrm{Ex}=$ Exports

Im=Imports.

We know from Cusack US Economy equation [3]

$\mathrm{Y}=\mathrm{e}^{0.1315}=114.05$

And

We know from Astro-Theology Mathematics [1]

$\mathrm{Y}=1 / \mathrm{Y}$

$\mathrm{Y}^{2}=1$

$\mathrm{Y}=1=100 \%$

$\mathrm{Y}=\mathrm{C}+\mathrm{G}+\mathrm{I}+\mathrm{S}+(\mathrm{EX}-\mathrm{IM})$

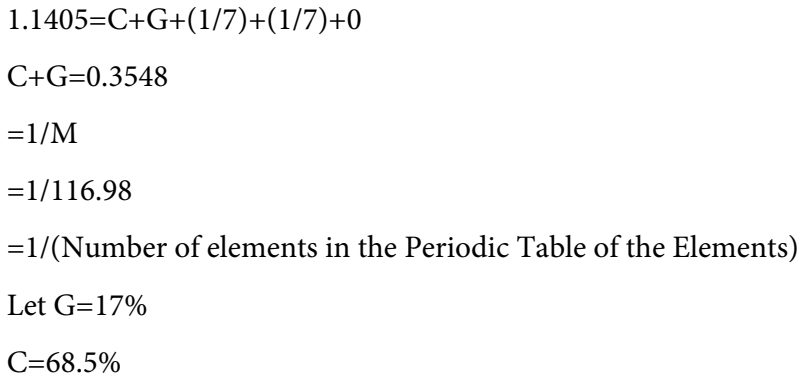

$=1 / \mathrm{M}$

From Permittivity in Physics $\varepsilon_{0}$ :

$\varepsilon_{\mathrm{R}} \times \varepsilon_{0}=(1+\mathrm{X}) \varepsilon_{0}$

$\varepsilon_{\mathrm{R}} /(1+\mathrm{X})=1$

$=1 / \mathrm{M}$

Where:

$\varepsilon=$ strain

M=Mass

$\mathrm{X}=0.9915$

$\varepsilon_{0} / 0.9915=0.8902 \sim c^{2}$

$1=100 \%=\mathrm{M}\left(1+\mathrm{c}^{2}\right)$

$\mathrm{GDP}=\mathrm{Y}=116(1+8.9)$

$\mathrm{Y}=23.4$

$=\operatorname{Ln} \pi$

*Corresponding author: Cusack PTE, Independent Researcher, DULE, 164 Sandy Point Rd, Saint John, NB, Canada, Tel: +5062143313; E-mail: St-michael@hotmial.com

Received October 10, 2017; Accepted October 16, 2017; Published October 23 2017

Citation: Cusack PTE (2017) Optimization of the GDP Equation. J Glob Econ 5 265. doi: 10.4172/2375-4389.1000265

Copyright: (c) 2017 Cusack PTE. This is an open-access article distributed under the terms of the Creative Commons Attribution License, which permits unrestricted use, distribution, and reproduction in any medium, provided the original author and source are credited. 
$=1 /$ cuz

$=1 /(\pi-\mathrm{e})$

$=1 / \mathrm{k}$ ( $\mathrm{k}$ is Stiffness of the individual consumer, the slope of the Supply curve)

$\mathrm{Y}=\mathrm{e}^{\pi}$ (This is the optimum GDP condition. $\mathrm{t}=\pi$ )

$\mathrm{Y}=\mathrm{e}^{\pi}=\mathrm{C}+\mathrm{G}+\mathrm{I}+\mathrm{S}+0$

$\mathrm{e}^{\pi}=\mathrm{C}+\mathrm{G}+(1 / 7)=(1 / 7)+0$

$\mathrm{C}=\mathrm{G}=22.8$

$\mathrm{C}-17 \%=22.8$

$\mathrm{C}=1 / \sqrt{ } 3=0.5774$ Or $54.47 \%$

$\mathrm{C}=\cot 60^{\circ}$ (This is the optimum Consumption Function)

C-G $=0.35 .48 \%$
$22.8 \%-35.47 \%=1.268=\rho$ (Density of the Ether) $[4]$

\section{Conclusion}

We see that knowledge of physical parameters can be used to determine optimization levels for the GDP Equation. Someone may program this into a computer program to produce a model of the national or even global economy.

\section{References}

1. Cusack P (2016) Astro-theology, Cusack's Universe. Journal of Physical Mathematics 7: 1-8.

2. Cusack $P$ (2017) Cusack US Economy Equation. Journal of Global Economics 5: $1-2$.

3. Cusack P (2017) An Algorithm for Economics: From GDP to the Consumer Journal of Global Economics 5: 1-3.

4. Cusack P (2016) The Ether: The Universal Material. Fluid Mechanics 3: 1-3. 